\title{
Research on the Test Method of the Concrete Expanded-Plates Pile
}

\author{
Yongmei Qian ${ }^{1, a}$, Qingyu Cheng ${ }^{2, b}$, Rongzheng Zhai ${ }^{3, c}$ \\ ${ }^{1}$ Jilin Jianzhu University, Changchun, China \\ ${ }^{2}$ Jilin Jianzhu University, Changchun, China \\ ${ }^{3}$ Jilin Jianzhu University, Changchun, China \\ a654675316@qq.com, ${ }^{\text {b1257720615@qq.com, }{ }^{\circ} 513917884 @ q q . c o m}$
}

\begin{abstract}
Keywords:The concrete expanded-plates pile (the CEP pile); Test method; The half-circle section pile; The large proportion pile

Abstract. This article discusses the current development of tests about pile foundation at home and abroad. According to the difference of test purpose and content, it is analyzed that several typical test methods of the Multi-Extruded-Expanded-Plates pile. In the article, due to the imperfections existed in the test, this article puts forward the site test method applied for the large proportion CEP pile with half-circle section, which enriches the test method of concrete pile and provides reference for other research on pile foundation.
\end{abstract}

\section{Introduction}

Because the CEP pile has advantages of high bearing capacity, smaller settlement, lower cost and so on, so it has been widely concerned in engineering project, at present, many scholars of china have made a lot of researches about the load transfer mechanism and the bearing capacity performance and failure mechanism of the CEP pile. In this paper, it is mainly discussed in detail that the development of the experiment research and several typical test method of the CEP pile, such as the comparative test, the load transfer law test, model test, and so on. Though the comparing and analyzing the various test methods from the different view of study object, they are summed up that some useful practical experience and optimization measures about the test of the CEP pile, such as experiment characteristics and process and so on. Finally, pointing at the problem during in the experimental study, it is put forward that a new test method named test of large proportion CEP pile with half-circle section in site, which provides a new way to study the CEP pile.

\section{The analysis of test method}

\section{The comparative test}

At present, the comparative test in site is mainly to make static load test for the CEP pile (or the expended-branches pile) and the common concrete poured pile with the equal diadetector section (named as the CCP pile in following), under the same site, same pile length, the same pile diadetector, in order to analyze and compare and collect the information from the aspects about the ultimate bearing capacity, the displacement at the top pile and economical value, etc.. Such as Jianping Jiang\&Hai Lu [1] the equal section and straight hole pile in the same site of different regions (Beijing, Tianjin, Henan, Nanjing, Zhejiang, Hainan), it is analyzed that the bearing performance of the CEP pile and the CCP pile through the of data comparative test, and the result is gotten that the bearing performance of the CEP pile is better than that of the CCP pile. Yanqing 
Zhang et al.[2],of which took comparative tests of the CEP pile and the CCP pile and the pile with only branches in the Yellow River region, they carried out that the ultimate bearing capacity of the pile with only branches and the CEP pile are respectively 3.36 times and 3.58 times of the CCP pile

The comparative test in site is a very mature method, which is also one of earlier methods used to research on the CEP pile. In the engineering which is used the CEP pile, it is needed to make static load test before the construction of pile and to compare the CEP pile with the CCP pile, in order to ensure to satisfy the requirement of engineering about bearing capacity and economic benefits and the displacement at the top of pile. In the process of the static load test, it is needed to ensure that the full proportion test of the CEP pile, in other words, to make a contrast test between the CEP pile and the CCP pile, that are used in actual engineering, so that the collected data has strong persuasive and reference value. In the test, the mainly date collected is the load and displacement at the top of pile, then to form curve of $Q \sim S$, and the ultimate bearing capacity of the CCP pile are ensured by the curve of $Q \sim S$.

In addition, before the test, it is needed to make geological exploration for test site and to form the physical index about soil of test site. On the one hand, the physical index can be used for the calculating the bearing capacity of single pile, on the other hand, in the test, in order to ensure enhance the bearing capacity and meet the design requirements, it is necessary to ensure the bearing plate of can be arranged on better soil layer. During the process of test, to pay attention to the construction technology influence on bearing capacity of the bearing plate

\section{The test about the regularity of load transfer.}

Jiaping Li [3] load-transfer of the CEP pile includes the side-friction of pile, the resistance of the plate or branches of pile, the resistance of the end of pile. Because of addition of the plate of pile, that makes the bearing capacity of the CEP pile to be far more than the CCP pile. Simultaneously, the Load-transfer is quite different comparing the CEP pile and the CCP piles. For the investigation of the regularity of load transfer, it is usually combined with static load test of practical engineering, in which reinforcement stress detector must be embedded in a specific location of pile, in order to collect the strain data, the load transfer mechanism of the CEP pile can be studied by using the collection strain data. For example, Deling Qian [4] has studied the load transfer mechanism of the CEP pile by the static load test, Zhankui Wang et al [5] have studied the load transfer mechanism of pile in the bridge foundation engineering which used the CEP pile.

The key to the successful test is the location of the reinforcement stress detector during the test of studying the regularity of load transfer in the CEP pile. Its main principle is, through strain data measured by the reinforcement stress detector, the axial force of each measured section is calculated to analyze the load transfer regularity. Reinforcement stress detector is not only set up on the main pile, but also is set up on the up and down of the plate, furthermore, it must be embedded in the upper and lower of each plate along the pile depth, while multiple plates are set up. this way it can be studied that the change curve of the axial force distribution up and down of the plate of pile, at the same time, it can be discussed whether the contribution of the bearing plate to the bearing capacity of pile is increased linearly with the increase of length of pile or not. In addition, in order to prevent not working caused by the reinforcement stress detector being not working, it must be ensured that the reinforcement stress detector has high successful rate when they are embedded.

About the test of the regularity of load transfer of the CEP pile, it can also be showed by the comparative test, in other words, in order to test the change rule of load along the pile length and to compare the load transfer of the CEP pile with the CCP pile and then to form the conclusion, the reinforcement stress detector should be uniformly set on the CCP piles at the same time. 


\section{The model test}

The existing experimental study on the CEP pile are mainly made to the pile of field engineering, such as the comparative test and load transfer test. The advantage of this approach is that can truly reflect the real working behavior of the pile and have higher reliability. But because of its higher cost the test can't be repeated many times, so it has a poor flexibility, and the systemically research is also difficult to be taken by the field test, because there are many factors effecting the bearing capacity and settlement magnitude. At this point, the indoor model test maybe is an effective test method. For example, Xuefeng Zhang et al [6] have made the test by using inherent silty clay and the small proportion CEP pile, Yongei Qian et al [7]made test by small model pile with half-circle section in order to study soil failure mechanism of the CEP pile.

In the model test, the settlement of pile is usually collected by the dial gauge placed on the top of the model pile, in different part of the model pile, strain gauges are arranged in order to measure the strain magnitude of the pile, at the end of pile and the bottom of the plate of pile, pressure box is placed to collect the pressure data of soil. The $Q \sim S$ curve of model pile and compressed deformation of soil can be drawn by contrast and analysis of the above date, thus it can be gotten that some more qualitative conclusion with extensive significance about the CEP pile. In addition, in the model test, the design and material selection of the model must be based on the similarity theory in order to make the experiment to be more close to the real condition.

Model test can also be used to study other aspects of the CEP pile, such as the group effect of the CEP pile, the difference of bearing capability when the CEP pile is set in the different soil layer; the influence of layer compaction effect to bearing capacity of the CEP pile and so on, and according to the test purpose, the research is focus on the relationship of influence factors (such as location, spacing, slope angle of the plates, etc.) of the CEP pile, then the universal rule is found out.

\section{Other test methods.}

About the squeezed and expanded effect of the soil surrounding the CEP pile, the test of Chengyuan $\mathrm{Lu}$ [8] is mainly the range affected of soil surrounding the CEP pile due to extrusion stress, it is put forward that the coefficient $\beta$ of coefficient of squeezed and expanded effect, Lijun Pan [9] studied the work properties of the CEP pile repeated load, it is concluded that, under the same repeated load, liquidity and creep deformation of cohesive soil made the deformation of soil surrounding the pile continually to increase, but stability of deformation is much faster in the silt soil.

\section{What problem existing about field test of the CEP pile}

Now, the field test of the CEP pile is restricted by the static load test with recording the curve of force-displacement of pile end, by setting reinforcement stress detector to measure the regularity of load transfer of pile. This traditional method only can measure the data, but can't see the change behavior of soil. Because of the structure itself of the CEP pile is different from the ordinary CCP pile, as which it is not as simple that the plate of the CEP pile make the changes of soil surrounding the pile because of the settle of the bearing plates, so it is very important to sure the failure behavior of soil surrounding the pile. At the same time, it is not allowed to be loaded up to failure when testing the engineering pile, and as a result, it is hard to get the ultimate load magnitude, so the ultimate load magnitude must be estimated by simulating and calculating and deducing. Because the underestimate of the ultimate bearing capacity, when making the test for testing pile, which can't be reached its maximum loading and damaged, so the ultimate bearing capacity of single pile can' $t$ be determined. 
The laboratory model test of the CEP pile has its unique advantages in many aspects, such as flexible design, simple operation, saving cost, etc. But there are the inevitable differences between the small proportion model test and the actual situation in the aspects of test materials, model proportion, reality of soil, and so on, so there is a certain deviation of the data from the test, which affects the final analyzing results.

\section{Test of large proportion the CEP pile under vertical compression}

In the above model test, Yongmei Qian's small model with half-circle section test has strong innovative. The pile used in test was made with half-circle section, and at the same time made a glass aquarium with special size (as shown in Fig.1). The side plain of half-circle section need to be closed to the interior surface of glass and cohesive soil is put into the aquarium to simulate the behave of the practical soil during the test, finally the static load test will be made, that are collected that the date of load and displacement, and it is watched of the failure behavior of the soil through the glass wall. The innovation of the test is that the change of the soil, from loading to destroy, can be clearly observed and the result of destructive soil can be taken pictures, this test overcome shortcomings of traditional test, from which only test data can be gotten and the real change situation of soil can't be seen.

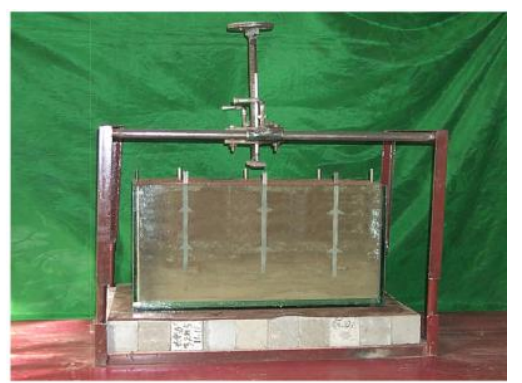

Fig1. The test device of small model pile with half-circle section

The new research method is put forward about the CEP pile, which is field test of the large proportion pile with half-circle section according to the Yongmei Qian's small proportion model test with half-circle section. The CEP pile of field test need to be made by reinforced concrete with half-circle section, by excavation at the side way of the pile, they are shown that the elevation of the pile and soil surrounding the pile, whose outside is sealed by reinforced glass in order to keep supporting of side, finally to make static load test on the pile and to collect data of load and displacement, the work together between the pile and soil can be observed clearly through the reinforced glass, as shown in Fig.2 and Fig.3.

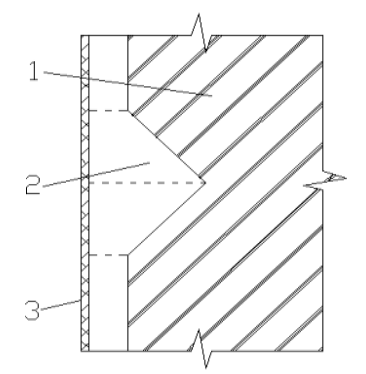

Fig2. The profile of large scale half-circle section pile (1 soil, 2 half-circle section pile, 3 Reinforced glass) 


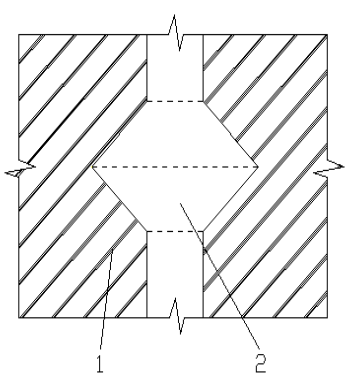

Fig3. The front view of large proportion pile with half-circle section (1 soil, 2 half-circle section pile)

The working mechanism of the CEP pile is complex, especially the work together between the pile and soil is more difficult to be determined, it is not applicable that the current theoretical analysis and model test used to estimate the working behavior of soil surrounding the pile. However, this kind of half-circle section test overcomes this weakness, it can truly reflect the behavior of work together between the pile and soil under the vertical compression, it also can be observed and recorded that the whole process of damaging soil and actual data is provided for theoretical analysis in the future. This method is a new type, so it also need to summarized and completed, such as test apparatus, the loading device, test material and test process and so on, in order to make this method has applicability and generalization.

\section{Conclusions}

In recent years, Chinese scholars have done a lot of theoretical research on the CEP pile, it has already been developed rapidly that the construction technology and equipment of the CEP pile, from the above of the paper, it can be seen that experimental study of the CEP pile gradually develops, and research direction is refined from qualitative to quantitative, and the research is more systematic. But the bearing capacity formulas of the CEP pile are mostly still defined by experience or half-experience, so in this aspect it also needs a lot of theoretical research and experimental data to support. In this paper, it is put forward that half-circle section field test, which provides a new method to study the CEP pile, and this method provides a better reference to other research on variable section pile, and it also promotes research on pile foundation and enlarging of application range.

\section{Acknowledgments}

This work is financially supported by National Natural Science Foundation of China (51278224).

\section{References}

[1] Jianping Jiang\&Hai Lu, The equal and straight pile in the same site of different places in Journal of construction technology, 4 (1) : 43 (2007)

[2] Yanqing Zhang\&HuiYuan. Hydraulic squeezed branch expansion/squeezed branch pile bearing performance test research in Journal of Beijing university of technology, 32 (10) : 879 (2006)

[3] Jiaping Li. Soil disturbance on the shear strength of soil, the influence mechanism research in Shanghai: Tong Ji University, master's degree thesis (2002)

[4] Deling Qian. The load transfer law of the CEP piles extrusion expansion and FEM simulation in Journal of geotechnical engineering.24 (3): 371 (2002)

[5] Zhankui Wang\& Yanwei Liang\&Sheng Jun Shi, Project in the vertical static load test of the CEP piles expansion research in Journal of ShanXi architecture, (17): 77 (2011)

[6] Xuefeng Zhang etc. The test of the work together with pile and soil of the CEP pile in Journal of Zhe Jiang university of technology, (4): 454 (2005) 
[7] Yongei Qian etc. The study of the CEP pile on failure mechanism of soil in Journal of geotechnical engineering, (12): 78 (2003)

[8] Chengyuan Lu. The research of the CEP pile in Journal of engineering survey, (6): 12 (2001)

[9] Lijun Pan. Engineering of the CEP pile under repeated load character research in Zhe Jiang University of technology master's degree thesis (2007) 